продуктах и отдыхе. Однако проблем, как в сфере туризма, так и в восстановлении финансово платежеспособного спроса россиян еще достаточно много и требует дальнейшего изучения.

1. Путин назвал улучшение жизни людей важнейшей целью (15.04.2021) // Режим доступа: https://rg.ru/2021/04/15/putin-nazval-uluchshenie-zhizni-liudej-vazhnejshej-celiu.html. Дата обращения: 02.12.21

2. Перечень поручений по итогам заседания Госсовета по обеспечению экономического роста и повышению уровня жизни граждан (27 июля 2012 года) // Официальный сайт «Президент России» / Режим доступа: http://www.kremlin.ru/events/state-council/16102. Дата обращения: 02.12 .21

3. Бедность и пандемия (28.05.20) / Официальный сайт ФОМ // Режим доступа: https://covid19.fom.ru/post/bednost-i-pandemiya. Дата обращения: 02.12.21

4. О чем мечтают россияне? (Аналитический обзор) Официальный сайт ВЦИОМ // Режим доступа: https://old.wciom.ru/index.php?id=236\&uid=10681. Дата обращения: 02.12 .21

\title{
Миндияхметова А.И.
}

Обеспечение экономической безопасности предприятия на основе управления затратами (на примере предприятия ОАО «Башсантехмонтаж»)

Башкирский Государственньй Университет (Россия, Уфа)

doi: 10.18411/trnio-12-2021-50

\section{Аннотация}

В данной статье рассмотрена взаимосвязь экономической безопасности предприятия и управление затратами. Взаимосвязь была продемонстрирована анализом затрат предприятия ОАО «Башсантехмонтаж» за 2018 -2020 г.г. За счет анализа основных производственнохозяйственных показателей деятельности предприятия была показана основная характеристика положения предприятия. В связи с этими показателями были предложены мероприятия по усовершенствованию снижения затрат, тем самым увеличение экономической безопасности предприятия ОАО «Башсантехмонтаж».

Ключевые слова: экономическая безопасность предприятия, управление затратами предприятия, анализ управления затратами предприятия, мероприятия по оптимизации затрат предприятия, себестоимость.

\section{Abstract}

This article examines the relationship between the economic security of the enterprise and cost management. The relationship was demonstrated by the analysis of the costs of the enterprise of JSC Bashsantehmontazh for 2018-2020. Due to the analysis of the main production and economic indicators of the enterprise, the main characteristic of the enterprise's position was shown. In connection with these indicators, measures were proposed to improve cost reduction, thereby increasing the economic security of the enterprise of JSC Bashsantehmontazh.

Keywords: economic security of the enterprise, cost management of the enterprise, analysis of enterprise cost management, measures to optimize enterprise costs, cost.

Управление затратами предприятия в системе экономической безопасности предприятия является немаловажным процессом. Поскольку проблема экономической безопасности финансово-хозяйственной деятельности предприятия на данный момент является актуальной, в связи с нестабильной ситуацией в стране. В целом актуальность данного исследования, заключается в том, что исследовал роль и место управления затратами в общей системе экономической безопасности предприятия, мы устанавливаем взаимосвязь между экономической безопасностью управление затратами.

Как утверждают различные авторы, определение экономической безопасности очень большое количество, однако в каждом определении присутствует - индикаторы оценки 
состояния экономической безопасности, параметры её обеспечения, угрозы и проблемы. Как правило, процесс управления затратами направлен на контроль и анализ затрат организации. [2]

Поиск и устранение внешних и внутренних угроз экономической безопасности предприятия тесно связана с затратами. Необходимо понять, даст ли устранение тех или иных угроз, состояние защищенности организации от воздействие внутренних и внешних угроз в долгосрочной перспективе.

Функции управления затратами подразделяются на: планирование, контроль, анализ и стимулирование. Все эти функции необходимы для успешного бизнес-процесса. Оценим уровень затрат и угроз экономической безопасности на примере ОАО «Башсантехмонтаж».

Данное предприятие занимается монтажом, ремонтом техники и вентиляционных систем производств, сооружение котельных установок, производство прокладок сетей теплогазоснабжение, водопровода и канализации, а также заготовка деталей сантехники.

Косвенные затраты в себестоимости продукции представлены следующими статьями:

1. расходы на заработную плату;

2. общепроизводственные и общехозяйственные расходы;

3. амортизация.

Анализ вышесказанных расходов производится с помощью сравнения фактической их величины на рубль произведённой продукции. Такой анализ показывает нам, как изменилась их доля выпущенной продукции. Рассмотрим динамику и структуру затрат производства в таблице 1.

Таблица 1

Динамика и структура затрат производства

\begin{tabular}{|c|c|c|c|c|c|c|c|}
\hline \multirow[b]{2}{*}{ Статья расходов } & \multicolumn{2}{|c|}{20182.} & \multicolumn{2}{|c|}{20192.} & \multicolumn{2}{|c|}{20202.} & \multirow{2}{*}{$\begin{array}{c}2020 \text { г. в } \\
\% \text { к } \\
20182 .\end{array}$} \\
\hline & тыс.руб. & $\begin{array}{c}6 \% \\
\text { uтогу }\end{array}$ & тыс.руб. & в \% к итогу & тыс.руб. & $\begin{array}{c}8 \% \kappa \\
\text { uтогу }\end{array}$ & \\
\hline Заработная плата & 5245 & 38,2 & 4710 & 40,6 & 4710 & 26,4 & 89,7 \\
\hline Амортизачия & 512 & 3,9 & 113 & 0,78 & 119 & 0,78 & 23,2 \\
\hline Коммунальные услуги & 1639 & 12,1 & 1787 & 12,4 & 5542 & 30,2 & 338,1 \\
\hline Страховые взносы & 1689 & 9,8 & 1522 & 11,5 & 1513 & 8,26 & 89,5 \\
\hline Прочие расходы & 4584 & 47,9 & 6205 & 41,0 & 6420 & 32,0 & 140 \\
\hline Итого & 13667 & 100,0 & 14337 & 100 & 18304 & 100 & 133,9 \\
\hline
\end{tabular}

Данные таблицы 2 показывают нам о росте затрат на производство на 33,9\%. в структуре значительный произошёл коммунальных услуг в 3,3 раза.

Как правило, затраты делятся на постоянные и переменные. Постоянные затраты не зависят от объёмов производства и реализации, а переменные напрямую зависит от объёмов производства. Однако от количества произведенных товаров и услуг, они постоянно изменяется в процессе предпринимательской деятельности. В таблице 2 представлены показатели эффективности управление себестоимости предприятия на выполнение работ и оказание услуг.

Таблица 2

Показатели эффективности управления затратами

\begin{tabular}{|c|c|c|c|c|}
\hline $\begin{array}{c}\text { Показатель } \\
\text { Выручка от реализованной продукиии, тыс. } \\
\text { руб. }\end{array}$ & 2018 г. & 2019 г. & 2020 г. & $\begin{array}{c}\text { Отклонение, } \\
2020 / 2018 \text { г. }\end{array}$ \\
\hline $\begin{array}{c}\text { Себестоимость реализованной продукции, } \\
\text { тыс. руб. }\end{array}$ & 13283 & 19795 & 21879 & +8596 \\
\hline \begin{tabular}{c} 
в том числе: \\
\hline - переменные затраты, тыс. руб.
\end{tabular} & 10017 & 14337 & 18304 & +4637 \\
\hline - постоянные затраты, тыс. руб. & 3650 & 3650 & 3720 & +70 \\
\hline
\end{tabular}




\begin{tabular}{|c|c|c|c|c|}
\hline Себестоимость 1 рубля продаж, руб. & 1,02 & 0,72 & 0,83 & $-0,18$ \\
\hline Прибыль от продаж, тыс. руб. & 690 & 5458 & 3375 & +2685 \\
\hline Рентабельность, \% & 2,1 & 1,52 & 1,64 & $-0,46$ \\
\hline
\end{tabular}

По данным таблицы 2, можно сказать что постоянные затраты к 2020 году увеличились на 15\% или на 913 тыс.руб., а переменные затраты снизились, что сопровождается ростом выручки.

На рисунке 1 рассмотрим зависимость рентабельности затрат от себестоимости.

Себестоимость 1 рубля продаж снизилась на 18 коп., это стало причиной снижения стабильности продаж.

По данным таблицы 3 и рисунка 1, можно сделать вывод, что эффективность управления себестоимостью, в 2018 году выше по сравнению с 2020 годом, об этом свидетельствует снижение себестоимости 1 рубля продаж, и как следствие снижение рентабельности затрат предприятия.

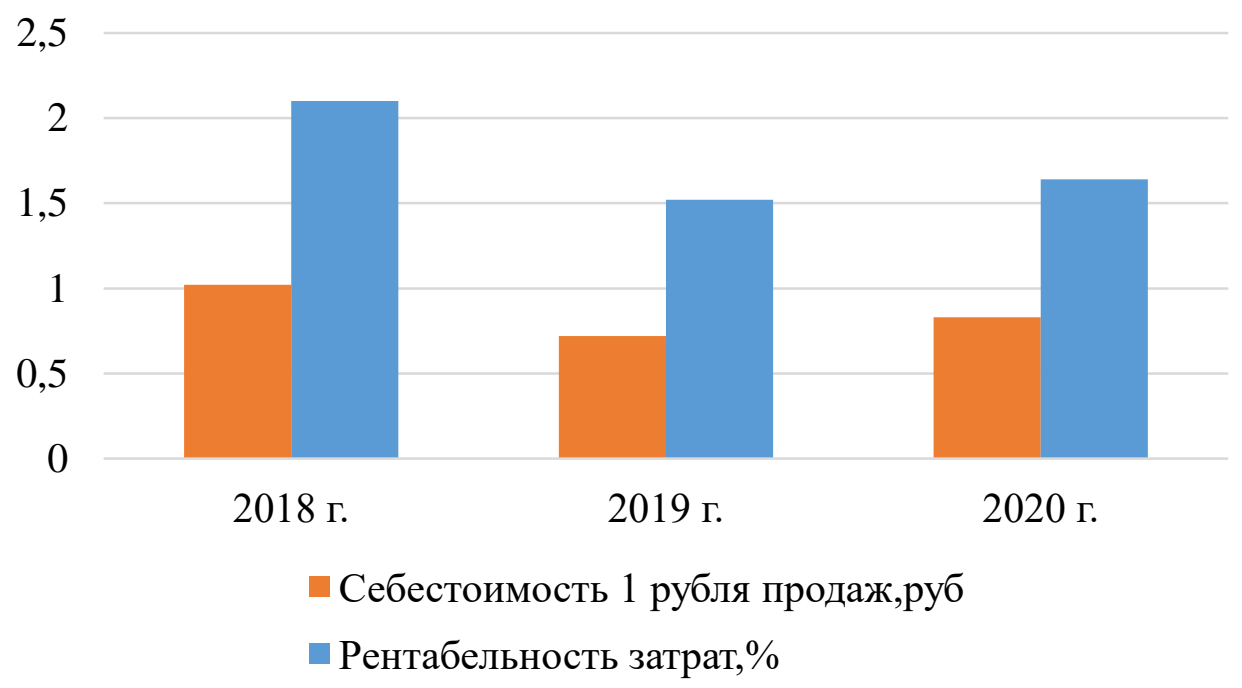

Рисунок 1. Зависимость рентабельности затрат от себестоимости (себестоимости 1 рубля продукции)

Постоянные и переменные затраты производства определяют себестоимость производства и продаж. Для этого рассмотрим динамику себестоимости 1 рубля продаж и динамика структуры прибыли от продаж (см.рис 2 и 3).

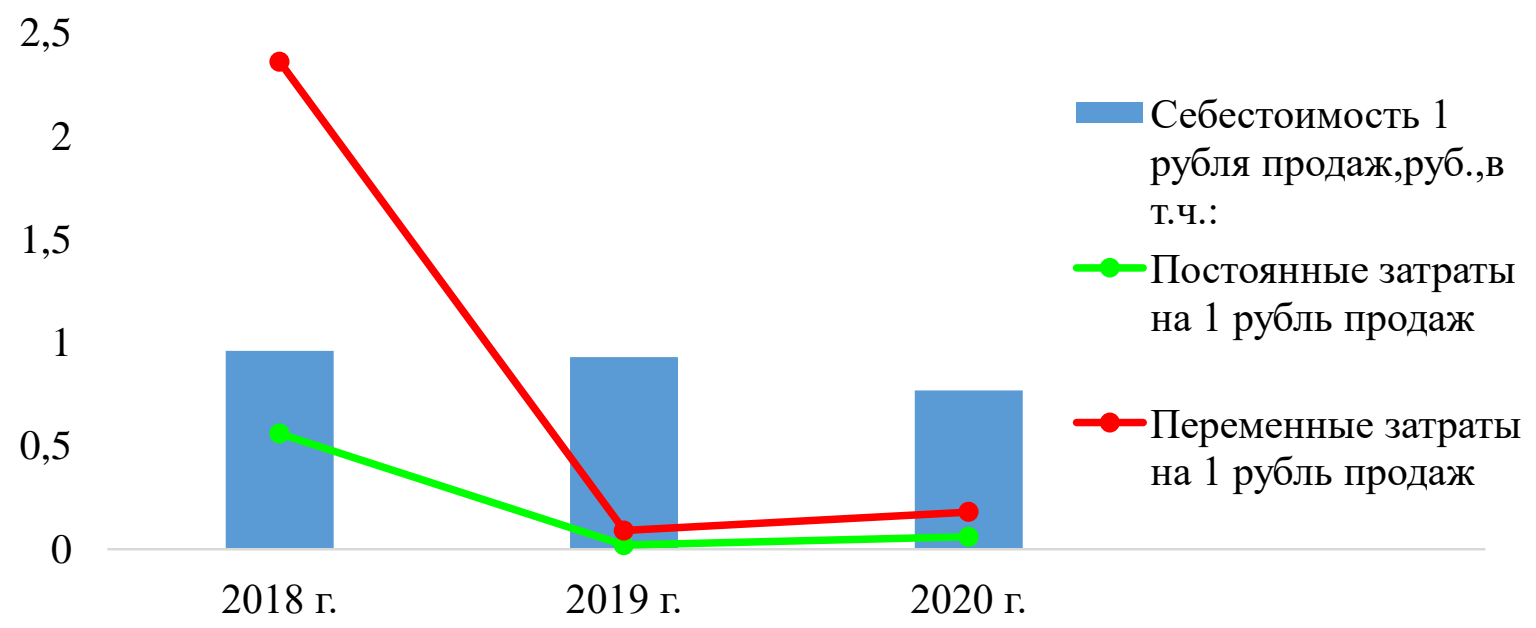

Рисунок 2. Динамика себестоимости 1 рубля продаж, \% 
Наиболее негативным фактором, оказавшим влияние на рост затрат на производство продукции, повлияло на изменение структуры производства. Таким образом, в структуре производства увеличился удельный вес менее рентабельных видов производства.

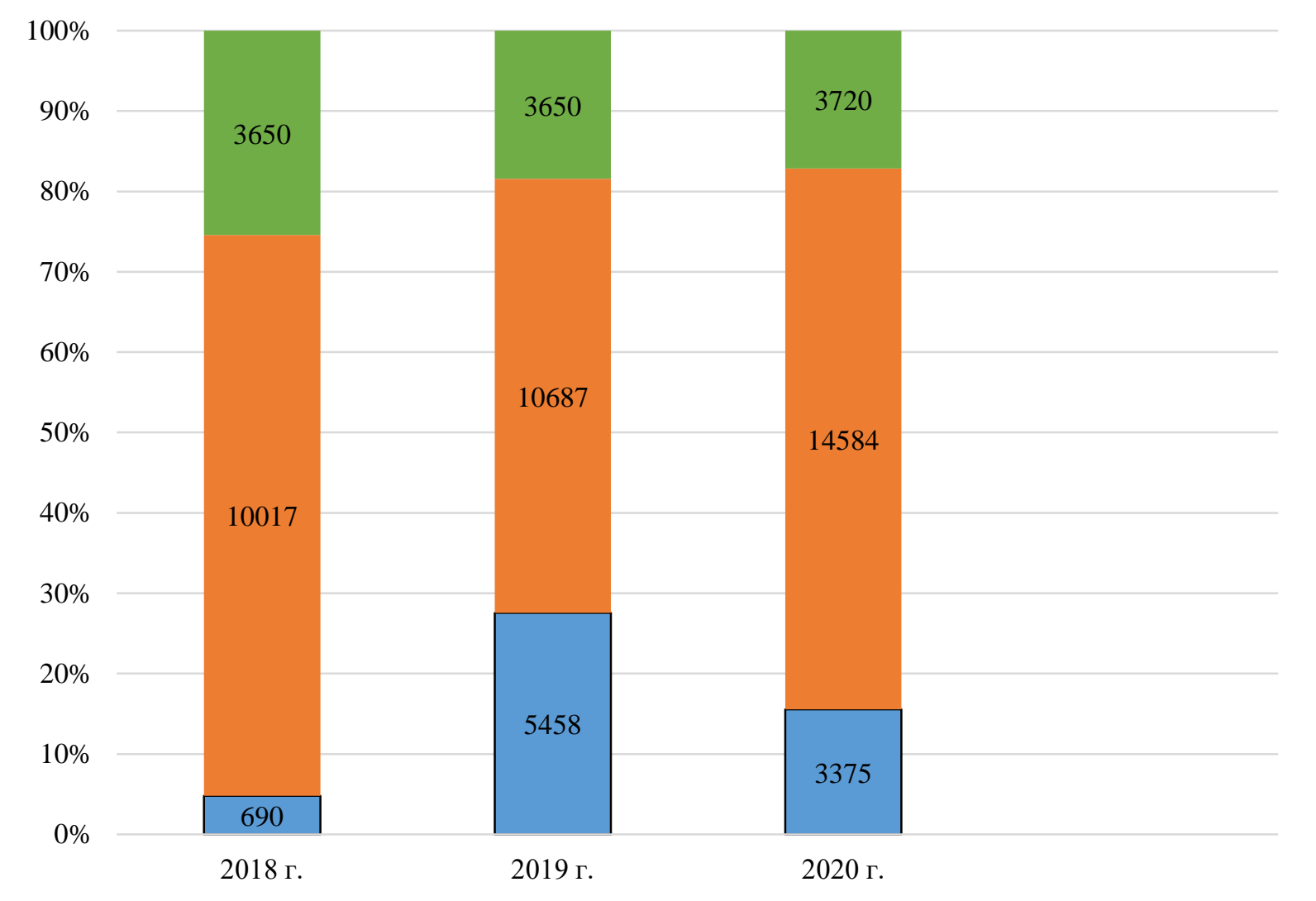

口Прибыль от продаж,тыс.руб. Переменные затраты,тыс.руб.

Постоянные затраты, тыс.руб.

Рисунок 3. Динамика структуры прибыль от продаж, \%

Рассмотрим пути обеспечения экономической безопасности на основе управления затратами. В таблице 3 представлен комплекс предлагаемых мероприятий для внедрения в OАО «Башсантехмонтаж».

Таблица 3

Комплекс предлагаемых мероприятий, рекомендованных для внедрения в ОАО «Башсантехмонтаж»

\begin{tabular}{|c|c|c|}
\hline Наименование мероприятия & Затратность & Устранение проблемь \\
\hline $\begin{array}{c}\text { Использование тепла недоливков для } \\
\text { нагревания поддонов изложнии }\end{array}$ & Беззатратное & $\begin{array}{c}\text { Сокращение затрат на инжекторный } \\
\text { газ }\end{array}$ \\
\hline $\begin{array}{c}\text { Реконструкичи дымоотводящегоо } \\
\text { тракта термической печи } \\
\text { производства поковок и штамповок }\end{array}$ & 7918 mысс.руб. & $\begin{array}{l}\text { Сокрашение топливных расходов в } \\
\text { результате устранения потерь газа }\end{array}$ \\
\hline $\begin{array}{c}\text { Приобретение } \\
\text { ичифровыхмегаомметров М6-4, } \\
\text { предназначенхых для измерения } \\
\text { сопротивления изолящии } \\
\text { электрических ичепей }\end{array}$ & 795 тысс.руб. & $\begin{array}{c}\text { Устранение потерь электрической } \\
\text { энергии в сетях системь ОАО } \\
\text { «Башсантехмонтаж» }\end{array}$ \\
\hline $\begin{array}{c}\text { Внедрение документа «Карта } \\
\text { сборки» }\end{array}$ & Беззатратное & $\begin{array}{c}\text { Стандартизащия прочесса ремонта } \\
\text { оборудования и ликвидащчия повторяемых } \\
\text { операщчй }\end{array}$ \\
\hline Оснащение рабочих GPRS-трекерами & 6775 mысс.руб. & $\begin{array}{c}\text { Ликвидация непроизводственных потерь } \\
\text { рабочего времени }\end{array}$ \\
\hline
\end{tabular}


Одним из важных мероприятий по оптимизации производственного процесса, является снижение коммунальных услуг, тем самым необходимо снизить энергоёмкость установленного оборудования.

Следующим мероприятием является применение карт, позволяющие сократить трудозатраты на ремонт и подготовительные работы, они также смогут использовать при выдаче дневных планов - заданий, так как содержат весь комплекс нормативно-справочная данных.

Для того чтобы показать эффективность данных мероприятий необходимо рассчитать финансовые показатели и точку безубыточности с прогнозом на 2021 год. (см. табл 4).

Расчет точки безубыточности, тыс. руб.

\begin{tabular}{|c|c|c|c|}
\hline Показатель & 2020 г.(факт.) & 2021 г.(прогноз) & Темп роста \\
\hline Выручка & 21879 & 25598 & 116,9 \\
\hline Постоянные затраты & 3720 & 3720 & 100 \\
\hline Переменные затраты & 14584 & 13124 & 89,9 \\
\hline Маржинальный доход & 18159 & 21347 & 117 \\
\hline Точка безубыточности & 0,80 & 1,19 & 148,7 \\
\hline
\end{tabular}

По данным таблицы можно заметить, что по прогнозу на 2021 год выручка увеличится, а переменные затраты снизятся. Увеличение маржинального дохода и, как следствие, точки безубыточности, свидетельствует нам о том, что предприятие будет стабильно после применения данных мероприятий и экономическая безопасность предприятия увеличится.

$$
* * *
$$

1. Тарасова, Т.Ф. Совершенствование методов управления текущими затратами в системе экономической безопасности// Актуальные проблемы инновационного развития экономики. - 2019. - С. 32-36.

2. Тюреев, В.К. Управление затратами на предприятии // Экономические науки. - 2018. - № 3 (31). - С. $62-68$.

\section{Некрасов Д.Д. \\ Компьютерный эксперимент в социально-экономических исследованиях и управлении предприятием}

Кубанский государственный аграрный университет имени И.Т. Трубилина

(Россия, Краснодар)

doi: 10.18411/trnio-12-2021-51

Научный руководитель: Затонская И.В.

\section{Аннотация}

В данной статье дается определение компьютерного эксперимента, его недостатки и сильные стороны, устанавливается его роль в исследовании социально-экономических систем и управлении предприятием, а также рассмотрены базовые проблемы исследуемых социально-экономических систем.

Ключевые слова: компьютерный эксперимент, управление, социальноэкономические исследования, экономика, анализ данных, модель, предприятие.

\section{Abstract}

This article gives a definition of a computer experiment, its shortcomings and strengths, establishes its role in the study of socio-economic systems and enterprise management, and also considers the basic problems of the studied socio-economic systems.

Keywords: computer experiment, management, socio-economic research, economics, data analysis, model, enterprise. 